\title{
Anastomose coledocoduodenal término-lateral em plano único com eversão da parede do colédoco em suínos ${ }^{1}$
}

\author{
One layer end to side choledochusduodenal anastomosis with evertion of the \\ choledochus wall in swines
}

\begin{abstract}
Luiz Roberto do Nascimento², Murched Omar Taha ${ }^{3}$, Djalma José Fagundes ${ }^{4}$, Paulo de Oliveira Gomes $^{4}$, Neil Ferreira Novo ${ }^{5}$

1. Resumo de Tese de Doutorado aprovada no Programa de Pós-Graduação em Técnica Operatória e Cirurgia Experimental da Universidade Federal de São Paulo - Escola Paulista de Medicina (UNIFESP-EPM).

2. Doutor em Medicina pelo Programa de Pós-graduação da Técnica Operatória e Cirurgia Experimental da UNIFESP-EPM.

3. Prof. Afiliado do Departamento de Cirurgia e Orientador do Programa de Pós-graduação em Cirurgia e Experimentação da UNIFESP-EPM.

4. Professor Adjunto do Departamento de Cirurgia e Coordenador do Programa de Pós-graduação em Cirurgia e Experimentação da UNIFESP-EPM.

5. Professor Adjunto da Disciplina de Bioestatística da UNIFESP-EPM.
\end{abstract}

\section{RESUMO}

Objetivo: Estudar anastomose coledocoduodenal término-lateral em plano único, com a eversão da mucosa do colédoco e sua implantação em segmento do intestino, confeccionando-se uma "neopapila" que estando recoberta por mucosa afastaria a possibilidade de estenose. Métodos: Foram estudados 30 porcos, machos, distribuídos em 3 grupos de 10 animais: Grupo I- controle-colédocoduodeno anastomose convencional. Grupo II- experimento-coledocoduodeno-anastomose com eversão da parede do colédoco (neopapila). Grupo III - simulado - isolamento e mobilização das vias biliares sem coledocotomia. Os parâmetros analisados foram o fluxo biliar e manometria pré e pós - operatória, endoscopia com 15 dias de PO, e com 30 dias os animais reoperados e avaliados do ponto de vista macro e microscópicos. Resultados: A fluxometria e a manometria mostraram diferenças entre o pré e o pós-operatória nos grupos I e II, mas não no III. Nos animais dos grupos I e II,ocorreu metaplasia intestinal e diminuição das fibras elásticas do colédoco. Todos os animais apresentaram dilatação coledociana. Conclusão: A técnica de realização de neopapila mostrou resultado semelhante à técnica convencional.

Descritores: Técnicas de sutura. Vias biliares. Ducto biliar comum. Duodeno. Suínos.

\begin{abstract}
Purpose: This article aims to study the one layer end to side choledochusduodenal anastomosis creating a "neopapila" which, because of the mucosa recovering it, would prevent stenosis. Methods: Thirty male pigs were distributed within 3 equal groups = Group I (control) - conventional choledochusduodenal anastomosis . Group II (experiment) - one layer end to side anastomosis with evertion of the choledochus wall (neopapila). Group III (sham) - isolation and mobilization of the biliar tract with no choledocotomy. We got the biliar flow and pressure (pre and postoperative) monitorized on the 15 PO day the animals went trough an endoscopy and on the 30 PO day they were operated and the tissues were analysed under macro and microscopic view. Results: Regarding to biliar flow and manometry there were differences between all groups but the III. Animals in groups I and II showed intestinal metaplasia and diminished elastic fibers in the choledochus. All
\end{abstract}


animals showed choledoco dilation. Conclusion: The proposed technique allowed the same results as the standard technique.

Key words: Suture technique. Bile Ducts. Common bile duct. Duodeno. Swine.

\section{Introdução}

As obstruções totais, parciais ou segmentares dos ductos biliares intra e/ou extra-hepáticos, podem levar ao comprometimento do fluxo natural da bile em diferentes graus, que modificam a composição bioquímica do sangue e a histologia do fígado ${ }^{1}$.

Entre as principais causas de obstrução do trânsito biliar inclui-se a seqüela de traumatismo do hepatocolédoco, papilite fibrosa com grande dilatação e alongamento do hepatocolédoco, estenose inflamatória do hepatocolédoco, calculose intrahepática, neoplasia de via biliar extra-hepática, neoplasia irressecável da papila duodenal, pancreatite crônica cefálica com obstrução coledociana, divertículos duodenais justa-papilares com obstrução biliar $^{2}$.

No entanto, a maioria das estenoses não neoplásicas ocorre por procedimentos operatórios iatrogênicos ${ }^{3}$.

A reconstrução do trânsito biliar pode se fazer por anastomose entre os cotos remanescentes do colédoco ou por uma anastomose bilio-digestiva. A opção por uma ou outra técnica depende de condições locais, de equipamento e preparo da equipe cirúrgica ${ }^{4}$.

O diâmetro do colédoco cranial e a intensidade do infiltrado inflamatório são as principais causas pelas quais as anastomoses bilio-digestivas podem evoluir para uma estenose ${ }^{4}$.

Em 1946, Mammana ${ }^{5}$ estudando as reconstruções do trânsito biliar com colédoco de calibre normal, realizou um tipo de anastomose colédoco - duodenal, chamando-a de "neopapila”, pelo seu aspecto semelhante com o de uma papila duodenal $^{6,7}$. Esta anastomose era, na realidade, uma colédoco-duodeno anastomose término-lateral com eversão da parede coledociana.

As vantagens dessa anastomose seriam: a parede interna da "neopapila" projetar-se na luz do duodeno e o orifício de sua desembocadura ser recoberto pela mucosa coledociana o que afastaria a possibilidade de uma retração cicatricial tardia, seguida de estenose. Estas vantagens foram observadas por meio de colangiografia endovenosa em cinco pacientes submetidos a esta anastomose, não tendo ocorrido nenhum processo cicatricial estenótico ${ }^{5}$.

Considerando que a técnica idealizada por Mammana, ${ }^{5}$ apresenta alguns princípios que eventualmente diminuiriam as complicações das anastomoses bilio-digestivas; que esta técnica ainda não foi estudada experimentalmente; que na pesquisa na base de dados não foi encontrado nenhum trabalho recente a respeito, pareceu relevante o estudo desta técnica com o objetivo de avaliar as possíveis vantagens desse procedimento.

\section{Métodos}

\section{Amostra}

Foram utilizados 30 suínos da raça Landrace (Sus scrofa domesticus), machos, jovens, pesando entre $11.700 \mathrm{~g}$ a $14.600 \mathrm{~g}$. Os animais foram fornecidos por um criador previamente selecionado e permaneceram no biotério por 15 dias antes do ato operatório, para adaptaçãp às condições ambientais.

Foram sorteados e distribuídos em três grupos de 10 animais: G-1, G-2 e G-3.

Os procedimentos operatórios realizados em cada grupo foram:

Grupo I - (controle) - Colecistectomia, coledocotomia e anastomose colédoco duodenal término-lateral em plano único..

Grupo II- (experimento) - Colecistectomia, coledocotomia e anastomose-colédoco duodenal término-lateral em plano único com eversão da parede coledociana.

Grupo III - (simulado) - Colecistectomia e isolamento circunferencial do colédoco terminal, sem coledocotomia.

A pesquisa foi realizada no Laboratório da Técnica Cirúrgica da Faculdade de Ciências Médicas de Pouso Alegre - FACIMPA, com Projeto Aprovado pela Comissão de Ética em Pesquisa do Hospital São Paulo, dentro do Programa de PósGraduação em Técnica Operatória e Cirurgia Experimental - UNIFESP-EPM. 


\section{Procedimentos}

Os animais foram pesados e submetidos a banho com água e sabão. Permaneceram em jejum de $24 \mathrm{~h}$ para ração e $12 \mathrm{~h}$ para água. Como medicação préanestésica utilizou-se acepromazina $2 \mathrm{mg} . \mathrm{Kg}^{-1}$; midazolan $1 \mathrm{mg} . \mathrm{Kg}^{-1}$ e atropina $0,44 \mathrm{mg} \cdot \mathrm{Kg}^{-1}$ de peso via intramuscular em seringas separadas, 30 minutos antes do início da anestesia.

Injetou-se tiopental sódico endovenoso na quantidade de $10 \mathrm{mg} . \mathrm{Kg}^{-1}$ e procedeu-se a intubação orotraqueal. Manteve-se a anestesia com halotano por inalação.

Com o animal colocado em decúbito dorsal horizontal sobre a mesa operatória,

realizou se uma laparotomia mediana, iniciandose no apêndice xifóide e prosseguindo em direção caudal até completar a extensão de 10 centímetros.

O ducto cístico foi isolado e cateterizado com sonda de polivinil $n^{\circ}$. 6 , até que seus orifícios da extremidade distal ficassem no interior do ducto colédoco. Foi fixado nessa posição com fio de algodão 3-0 (Figura 1).

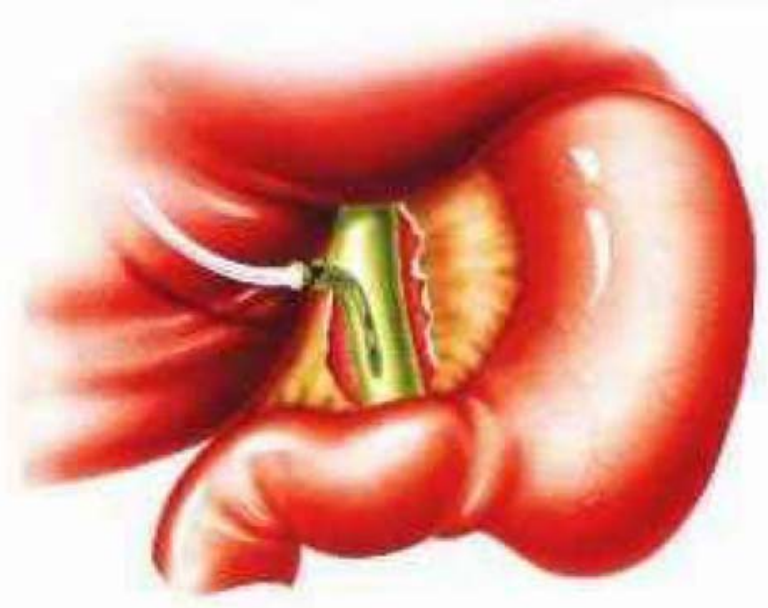

FIGURA 1 - Desenho mostra a sonda de polivinil posicionada no colédoco.

Com a sonda posicionada, aguardou-se que por refluxo, houvesse o preenchimento total de sua extensão com bile e a seguir conectou-se esta sonda a um fluxômetro, o que possibilitou a medição do Fluxo (F1) e da Pressão residual final (PRF1),

Foi então realizada a colecistectomia em todos os animais no grupo I, realizou-se uma anastomose colédoco duodenal término-lateral em plano único seguindo os seguintes tempos:

Isolamento do colédoco nos seus $1,5 \mathrm{~cm}$ distais junto ao duodeno (Figura 2). O diâmetro externo (D1) do colédoco foi medido com paquímetro.

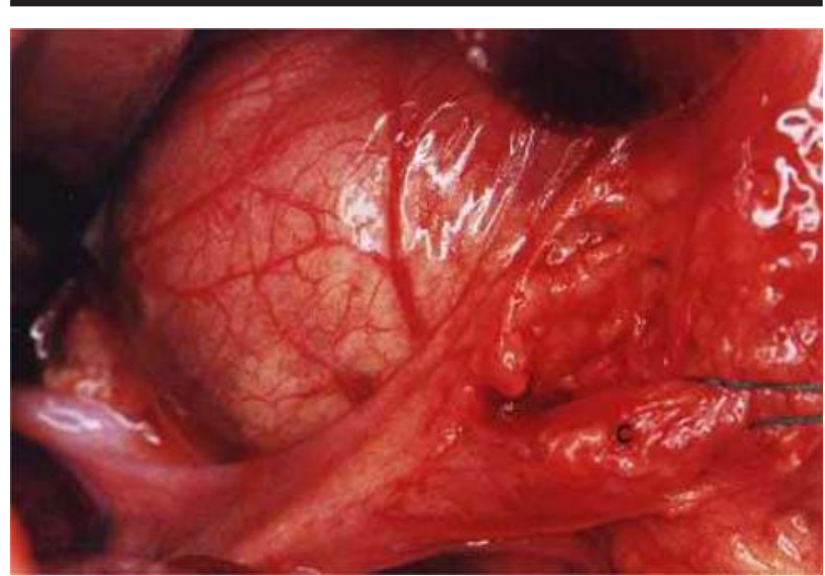

FIGURA 2 - Fotografia do ato operatório que mostra o colédoco (C) isolado junto ao duodeno.

O ducto colédoco foi seccionado a $0,5 \mathrm{~cm}$ da borda duodenal, fechando-se o coto distal com fio de polipropileno 5-0 com pontos separado. (Figura 3).

A seguir incisou-se o duodeno longitudinalmente, numa extensão do calibre do colédoco, na sua parede lateral direita em todas as suas camadas, $2 \mathrm{~cm}$ abaixo do fechamento do coto distal do colédoco. Iniciouse a anastomose do coto proximal pela região posterior do colédoco da porção cranial para a caudal, passando-se a agulha em pontos totais na parede do colédoco e duodeno. O nó foi atado para fora da luz das vísceras. Os pontos foram eqüidistantes $2 \mathrm{~mm}$ até completar toda a circunferência do colédoco (Figuras 4, 5 e 6).

No grupo II foi realizada uma anastomose colédoco-duodenal término- lateral em plano único, com eversão de parede coledociana e com pontos separados. Os tempos operatórios foram semelhantes ao grupo I até o tempo de secção e isolamento do colédoco (Figura 4). A seguir fez-se uma incisão longitudinal de $3 \mathrm{~mm}$ na parede anterior do colédoco (Figura 7). Fez-se a eversão da borda do coto proximal do colédoco, fixando a borda evertida com três pontos: dois anteriores, sendo um em cada borda incisada (Figura 8) e o terceiro ponto na região posterior (Figura 9).

Incisou-se o duodeno longitudinalmente, na 


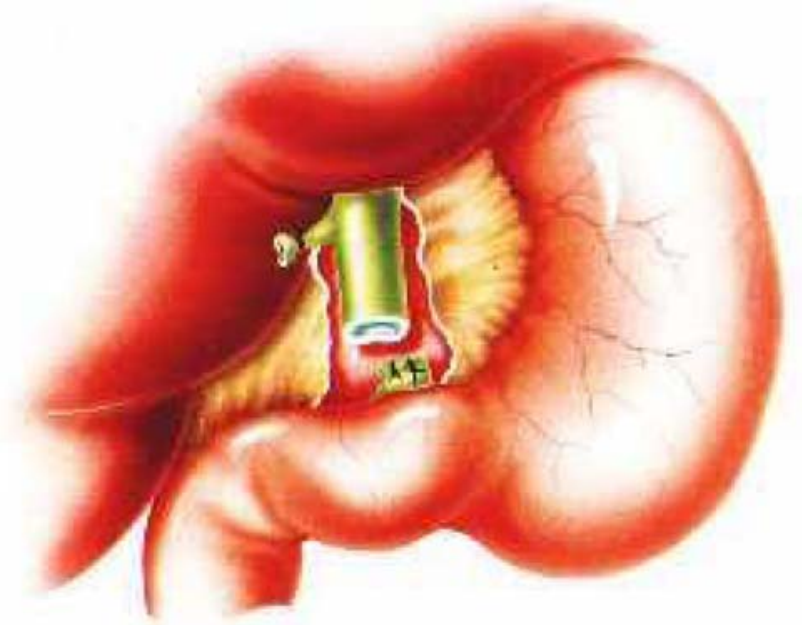

FIGURA 3 - Desenho mostra o colédoco seccionado com seu coto distal suturado.

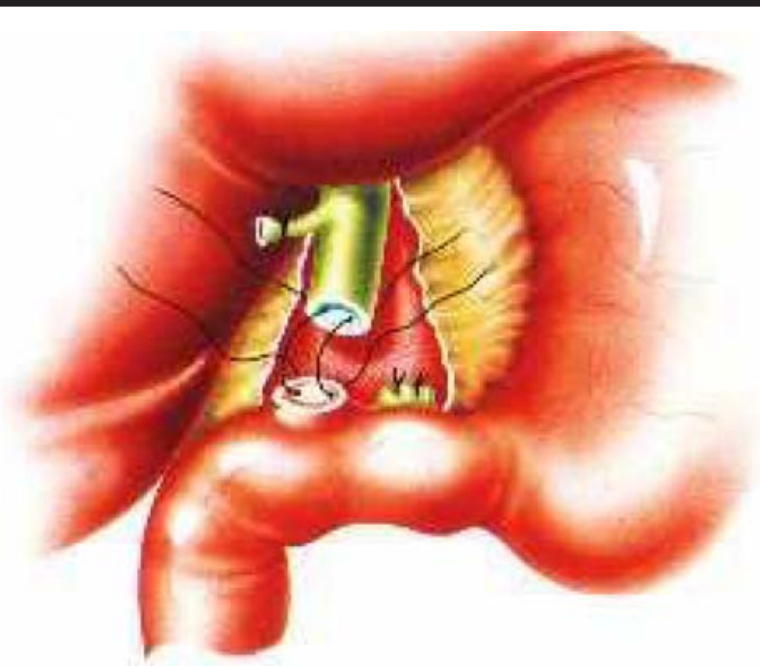

FIGURA 4 - Desenho mostra a sutura da parede posterior colédoco à parede posterior do duodeno.

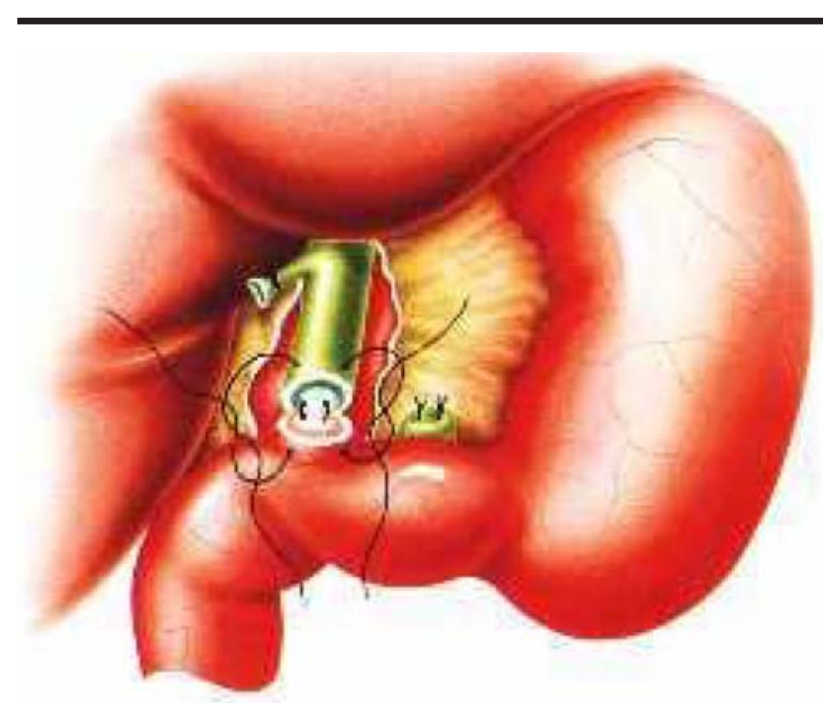

FIGURA 5 - Desenho mostra a sutura da parede anterior do colédoco à parede anterior do duodeno.

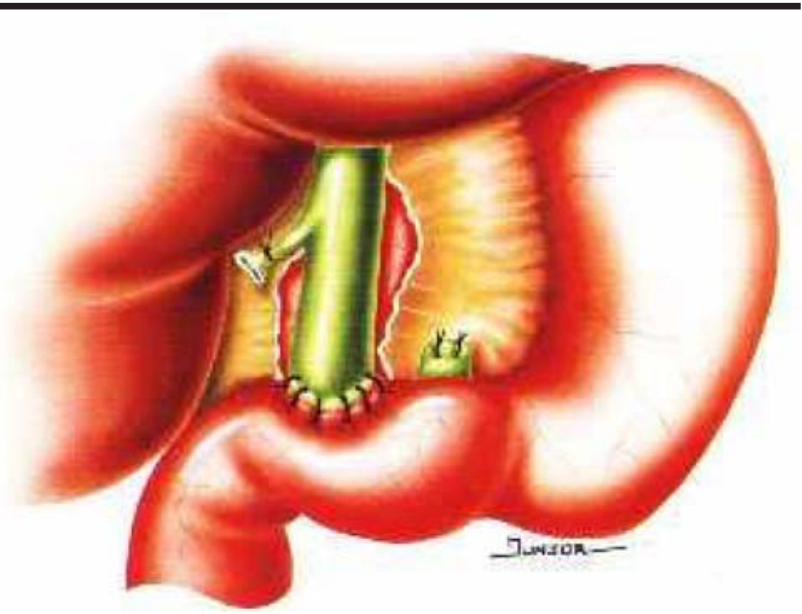

FIGURA 6 - Desenho mostra a anastomose do Grupo I concluída.

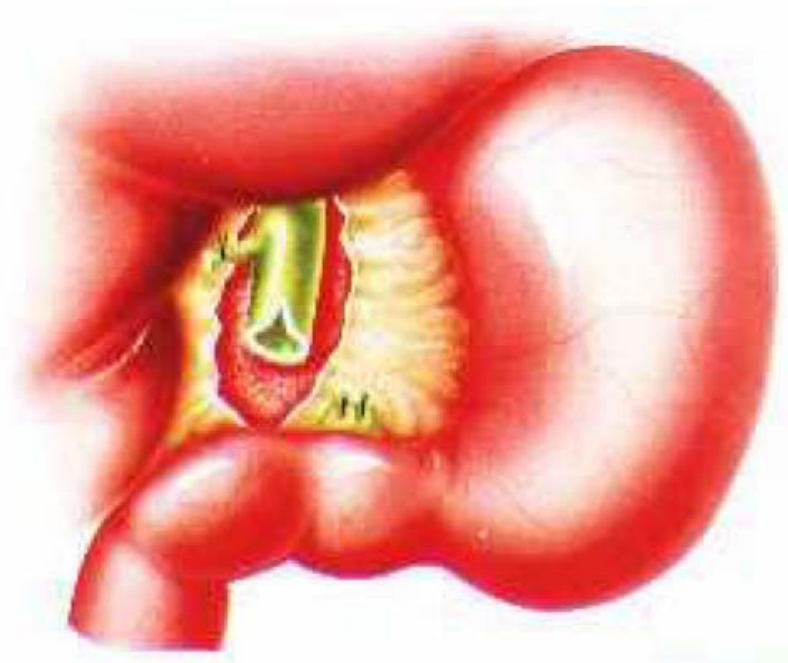

FIGURA 7 - Desenho mostra a incisão longitudinal de 3 mm na parede anterior do colédoco.

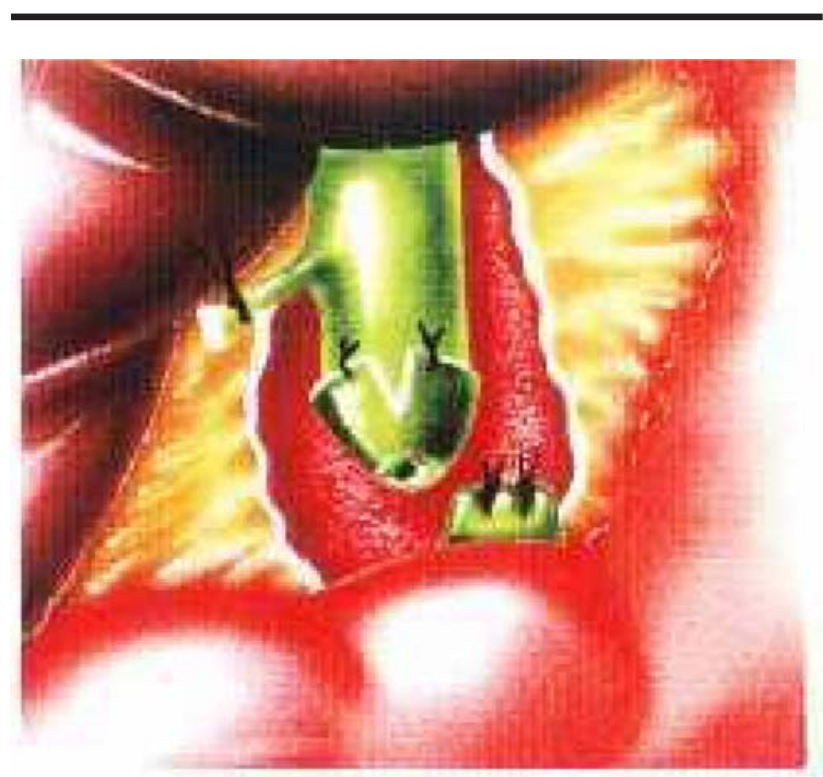

FIGURA 8 - Desenho mostra o detalhe da eversão da parede do colédoco. 


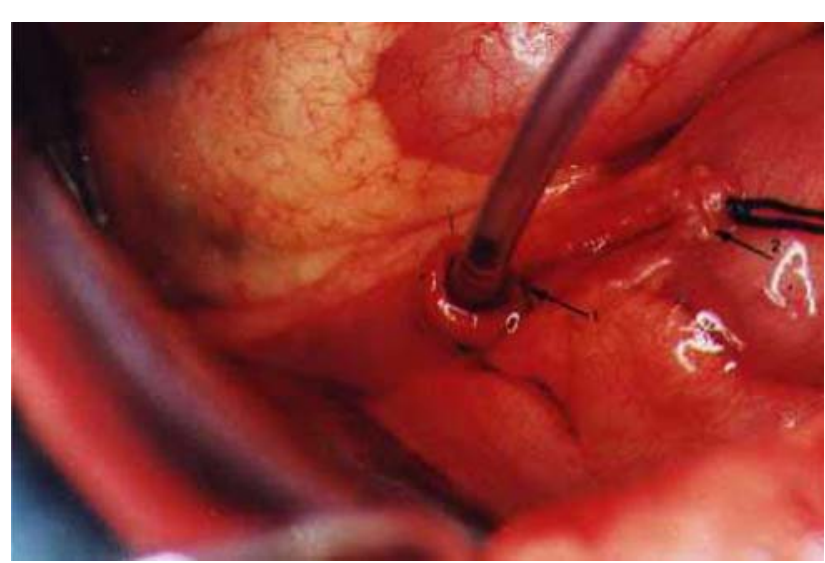

FIGURA 9 - Fotografia da operação que mostra o aspecto operatório da eversão da parede coledociana, com o ponto de fixação na parede posterior do colédoco (seta 1 ) e coto distal do colédoco fechado (seta 2). A sonda na luz coledociana foi para melhor efeito fotográfico.

mesma extensão do calibre do colédoco, na sua parede lateral direita em todas as suas camadas e iniciou-se a anastomose pela região posterior do colédoco no sentido crânio- caudal, passando-se a agulha na região posterior do colédoco, sem transfixar sua luz saindo o fio pela mucosa evertida. Passou-se a agulha pela mucosa do duodeno saindo na sua serosa. A seguir sutura-se as regiões laterais e finalmente a região anterior.

Os pontos foram eqüidistantes $2 \mathrm{~mm}$, com os nós atados pela parte extra-luminal (Figuras de 10 a 15 ).

Ambas as anastomoses foram realizadas com fio de polipropileno 6-0 encastoados em agulha atraumática de $1 \mathrm{~cm}$.

No grupo III seguiu-se o mesmo procedimento de ambos os grupos anteriores até o tempo que se isola circunferencialmente o colédoco nos seus $1,5 \mathrm{~cm}$ distais junto ao duodeno. O colédoco não foi seccionado.

No $15^{\circ}$ pós operatório os animais foram submetidos a duodenoscopia com fibroduodenoscopio. Durante a endoscopia pesquisou-se na anastomose a presença de edema, resíduos fixos no orifício da anastomose, áreas de necrose, diminuição do diâmetro e saída de bile normal ou de secreção purulenta.

No $30^{\circ}$ dia pós-operatório, os animais foram anestesiados de modo idêntico a primeira operação e em seguida reoperados. Foi inspecionado e analisado o aspecto da cicatrização, presença de

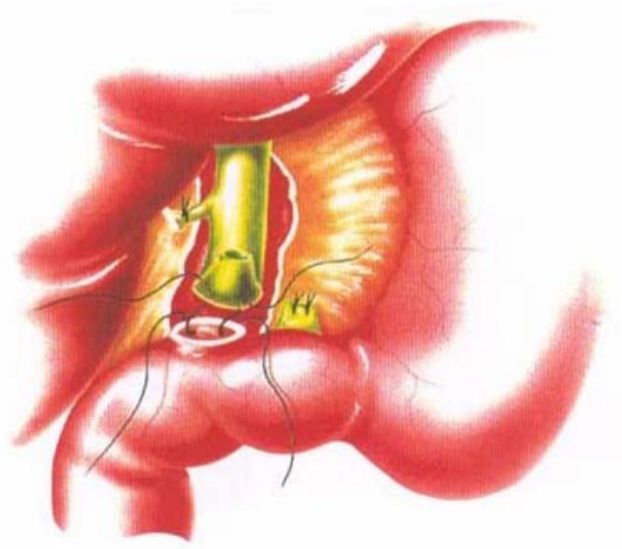

FIGURA 10 - Desenho mostra a sutura da parede posterior da eversão colédoco com a parede posterior do duodeno.

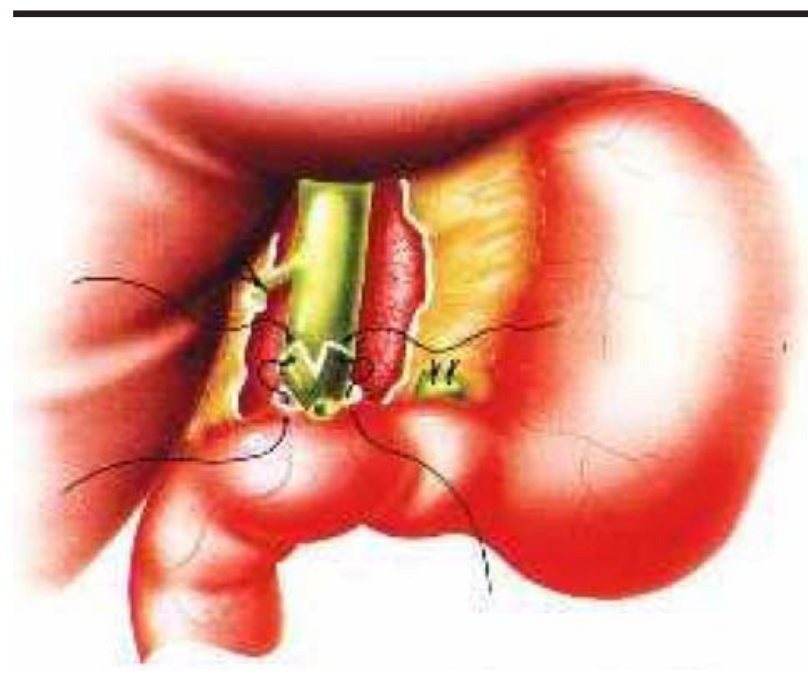

FIGURA 11 - Desenho mostra a sutura da parede anterior da eversão com a parede anterior do colédoco.

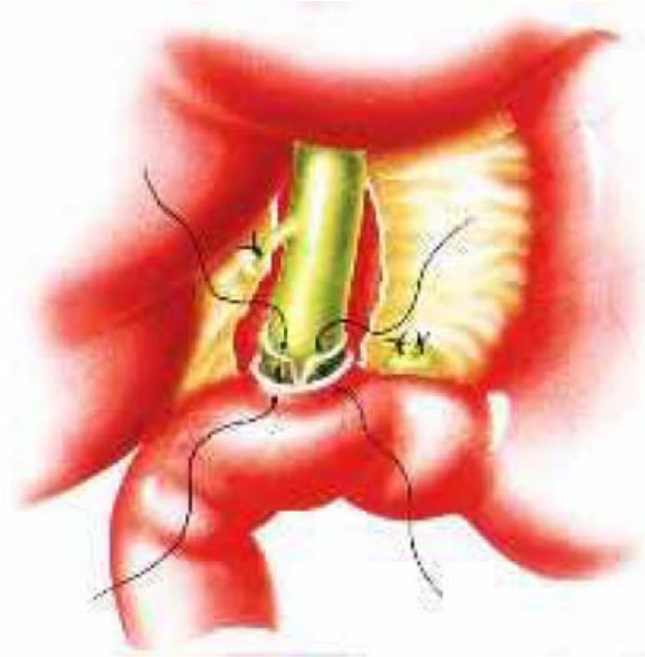

FIGURA 12 - Desenho mostra a porção evertida do colédoco sendo introduzida no duodeno. 


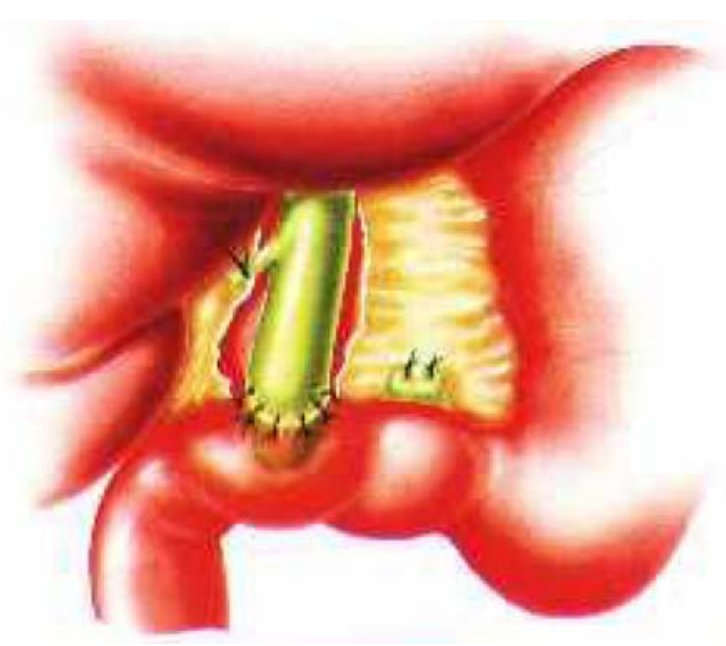

FIGURA 13 - Desenho mostra a anastomose do Grupo II concluída. (Aspecto externo).

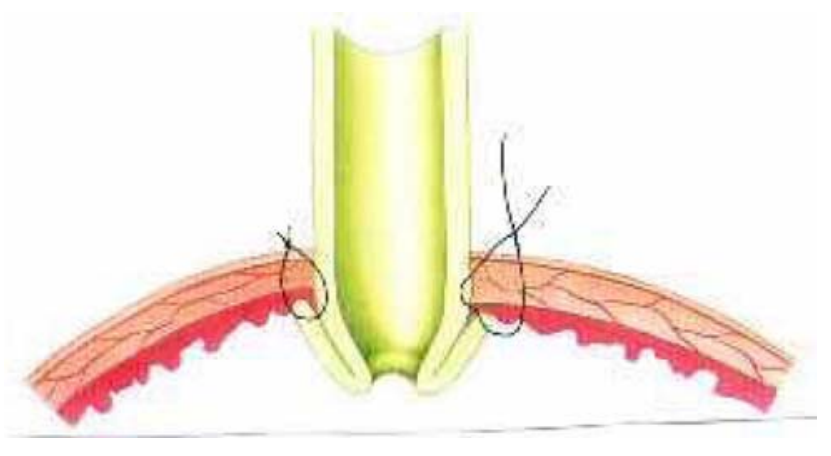

FIGURA 14 - Desenho mostra corte longitudinal da anastomose do Grupo II (Aspecto interno).

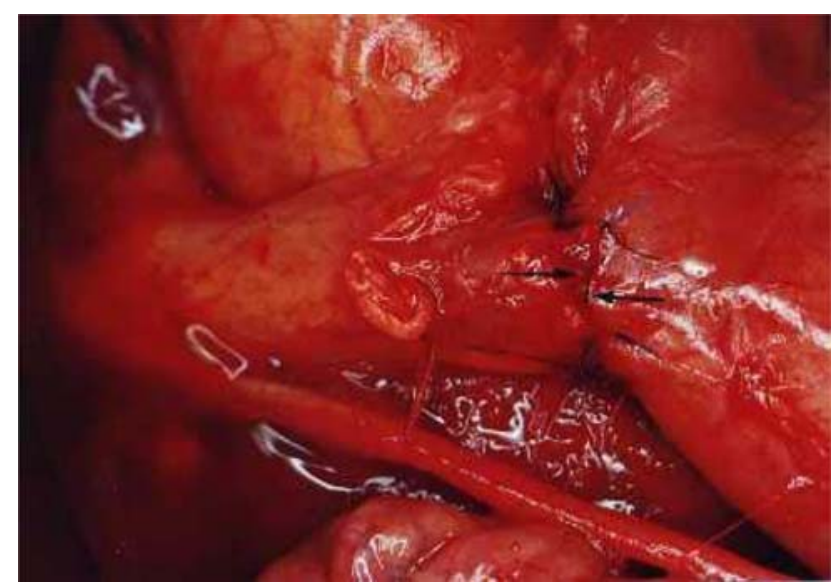

FIGURA 15 - Fotografia do ato operatório mostra o aspecto final da operação do Grupo II. (setas). abscesso e hernia incisional, foi realizada a inspecção da cavidade abdominal e anotada a presença de peritonite e $\mathrm{o}$ aspecto das aderências.

O colédoco foi isolado e seu calibre externo medido com o paquímetro (D2).

O ducto cístico foi isolado e cateterizado com cateter $n^{\circ}$ 6. Realizou-se a fluxometria (F2) e a medição da pressão residual final (PRF2). A seguir retirou-se a peça operatória, tendo como limites o ducto hepático direito e esquerdo junto ao hilo hepático e a $1^{\mathrm{a}}$ e $2^{\mathrm{a}}$ porções do duodeno.

Após a retirada da peça operatória, o colédoco foi seccionado e o diâmetro da anastomose foi calculado por meio da fórmula $\mathrm{C}=2$ ðr. As túnicas da anastomose colédoco duodenal foram consideradas com boa coaptação, do ponto de vista macroscópico, quando se notava na zona de anastomose continuidade e uniformidade na integração das bordas dessas estruturas e com má coaptação, quando se notava na zona de anastomose afastamento parcial ou total, falta de uniformidade na integração das bordas dessas estruturas ou fístula.

Na análise das lâminas procurou-se identificar a eversão da parede coledociana, o aspecto da coaptação na zona da anastomose na sua face interna e externa, presença ou ausência de fístula, tecido cicatricial, erosão, úlcera, necrose, infiltrado linfomonocitário, infiltrado de neutrófilos e reação de corpo estranho. No colédoco procurou-se identificar hiperplasia epitelial, atipia celular, atrofia do epitélio, metaplasia intestinal e quantificar as fibras elásticas.

Para análise dos resultados foram aplicados o Teste "t”, a Análise de Variância e o Teste do qui quadrado ( $\alpha$ d” 0,05) .

\section{Resultados}

Houve aumento no diâmetro externo do colédoco (Tabela 2) e no peso corpóreo (Tabela 1 ) de todos os animais, comparando-se a operaçâo e a reoperação, sem diferença entre os grupos.

No mesmo período, observou-se aumento do fluxo biliar (Tabela 3) e diminuição da pressão residual final (Tabela 4 ) mas apenas nos grupos I e II.

Ocorreu metaplasia intestinal no coledoco nos grupos I e II (Tabela 5) e a presença de fibras elásticas (Tabela 6), foi menor no grupo III em relação aos grupos I e II. Nos demais parâmetros analisados não foram constatadas diferenças significantes. 
TABELA 1 - Suínos do grupo I, II e III segundo o peso ( g ) na operação e reoperação.

\begin{tabular}{|c|c|c|c|c|c|c|c|c|}
\hline \multirow[b]{2}{*}{ OP } & \multicolumn{3}{|c|}{ GRUPO I } & \multicolumn{2}{|c|}{ GRUPO II } & \multicolumn{3}{|c|}{ GRUPO III } \\
\hline & REOP & $\Delta \%$ & OP & REOP & $\Delta \%$ & OP & REOP & $\Delta \%$ \\
\hline $\begin{array}{l}\text { X13010 } \\
\text { DP169,47 }\end{array}$ & $\begin{array}{l}14950 \\
1882,22\end{array}$ & 16,19 & $\begin{array}{l}12950 \\
1069,00\end{array}$ & $\begin{array}{l}14970 \\
1487,87\end{array}$ & 15,37 & $\begin{array}{l}13420 \\
927,12\end{array}$ & $\begin{array}{c}15690 \\
2182,98\end{array}$ & 18,15 \\
\hline
\end{tabular}

TABELA 2 - Suínos dos grupos I, II e III segundo o diâmetro externo (mm) do colédoco na operação e reoperação.

\begin{tabular}{|c|c|c|c|c|c|c|c|c|}
\hline \multicolumn{3}{|c|}{ GRUPO I } & \multicolumn{3}{|c|}{ GRUPO II } & \multicolumn{3}{|c|}{ GRUPO III } \\
\hline OP & REOP & $\Delta \%$ & OP & REOP & $\Delta \%$ & OP & REOP & $\Delta \%$ \\
\hline $\mathrm{X} \quad 5,21$ & 14,16 & 167,41 & 5,58 & 13,28 & 151,49 & 5,75 & 9,20 & 64,65 \\
\hline DP 0,60 & 5,74 & & 1,26 & 6,00 & & 1,16 & 2,66 & \\
\hline
\end{tabular}

TABELA3 - Suínos dos grupos I,II e III segundo a fluxometria na operação e reoperação (ml.min ${ }^{-1}$ ).

\begin{tabular}{|c|c|c|c|c|c|c|c|c|}
\hline \multirow[b]{2}{*}{ OP } & \multicolumn{3}{|c|}{ GRUPO I } & \multicolumn{2}{|c|}{ GRUPO II } & & \multicolumn{2}{|c|}{ GRUPO III } \\
\hline & REOP & $\Delta \%$ & $\mathrm{OP}$ & REOP & $\Delta \%$ & OP & REOP & $\Delta \%$ \\
\hline $\begin{array}{lr}X & 18,30 \\
\text { DP } & 2,93\end{array}$ & $\begin{array}{r}19,40 \\
3,35\end{array}$ & 10,77 & $\begin{array}{r}18,00 \\
1,95\end{array}$ & $\begin{array}{r}19,70 \\
1,15\end{array}$ & 10,03 & $\begin{array}{r}16,31 \\
3,85\end{array}$ & $\begin{array}{r}17,60 \\
3,83\end{array}$ & 8,62 \\
\hline
\end{tabular}

TABELA 4 - Suínos dos grupos I, II e III segundo a pressão residual final em cm de água na operação (PRF1 ) e na reoperação (PRF2) em cm de água.

\begin{tabular}{|c|c|c|c|c|c|c|c|c|}
\hline \multirow[b]{2}{*}{ OP } & \multicolumn{3}{|c|}{ GRUPO I } & \multicolumn{2}{|c|}{ GRUPO II } & & \multicolumn{2}{|c|}{ GRUPO III } \\
\hline & REOP & $\Delta \%$ & $\mathrm{OP}$ & REOP & $\Delta \%$ & $\mathrm{OP}$ & REOP & $\Delta \%$ \\
\hline $\begin{array}{lr}X \quad 5,90 \\
\text { DP } 267\end{array}$ & $\begin{array}{c}4,15 \\
2,02\end{array}$ & $-24,93$ & $\begin{array}{l}6,50 \\
2.28\end{array}$ & $\begin{array}{l}4,37 \\
1,69\end{array}$ & $-24,25$ & $\begin{array}{l}6,30 \\
2,23\end{array}$ & $\begin{array}{l}6,10 \\
176\end{array}$ & 2,07 \\
\hline
\end{tabular}

TABELA 5 - Suínos dos grupos I, II e III segundo a presença de metaplasia no colédoco.

\begin{tabular}{lcccr}
\hline Grupo & Sim & Não & Total & $\%$ \\
\hline I & 6 & & & 60 \\
II & 7 & 4 & 10 & 70 \\
III & 0 & 10 & 10 & 0 \\
& & & 10 & 43,33 \\
\hline Total & 13 & 17 & 30 & \\
\hline
\end{tabular}


TABELA 6 - Suínos dos grupos I, II e III segundo a porcentagem de fibras elásticas no colédoco.

\begin{tabular}{cccc}
\hline & Grupo I & Grupo II & Grupo III \\
\hline & & & \\
\hline $\begin{array}{c}\text { Média } \\
\text { DP }\end{array}$ & 11,73 & 11,51 & 16,48 \\
\hline
\end{tabular}

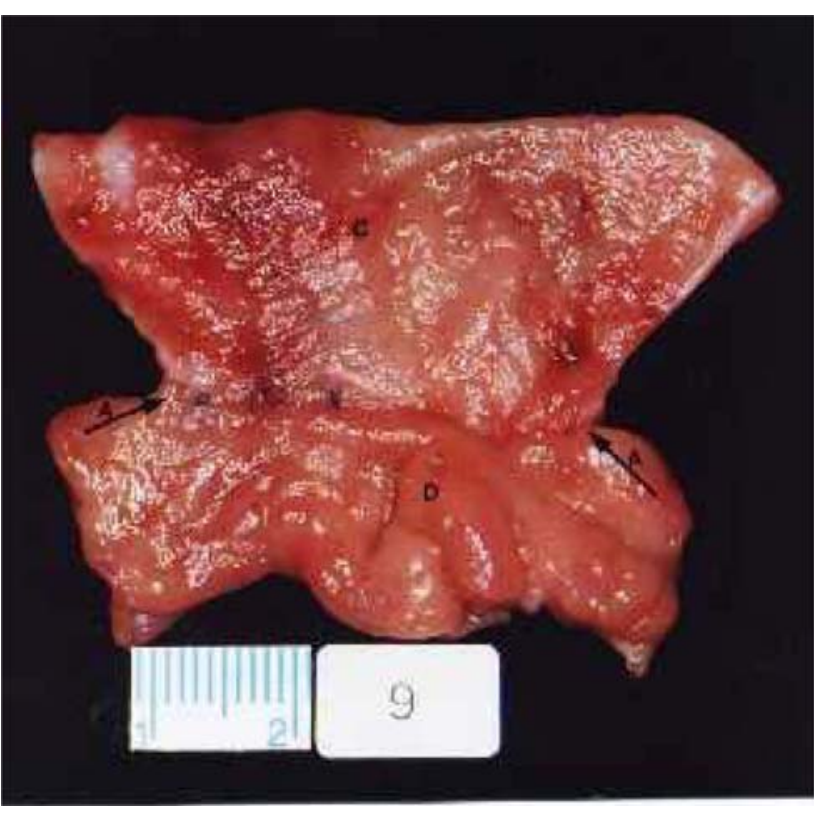

FIGURA 16 - Fotografia mostra a peça operatória aberta longitudinalmente. Colédoco dilatado (C), anastomose ampla (A) e duodeno (D). Suíno 9. Grupo I.

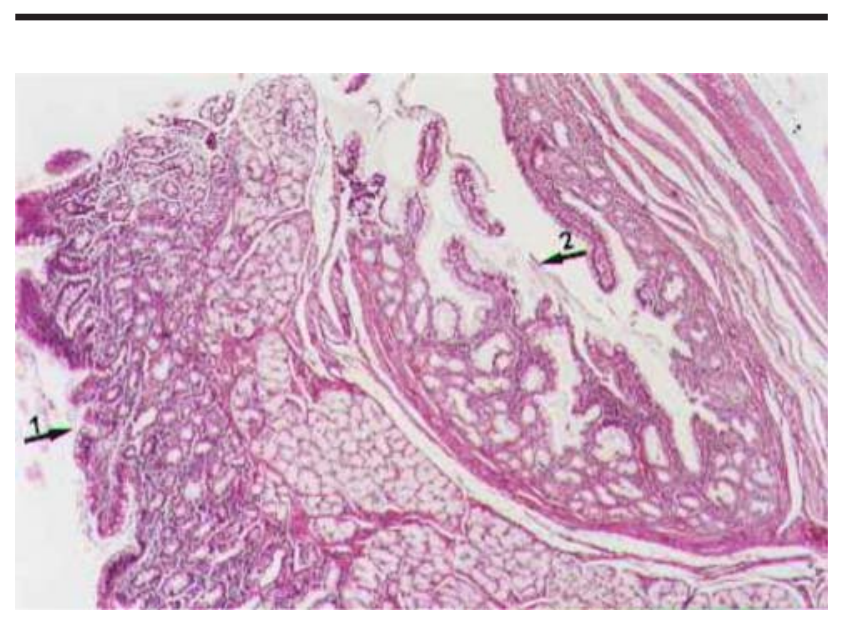

FIGURA 18 - Fotomicrografia da região da papila mostrando a mucosa duodenal (seta 1) continuando com a mucosa do colédoco (seta 2). Grupo III. Aumento 60x. Coloração pela hematoxilinaeosina.

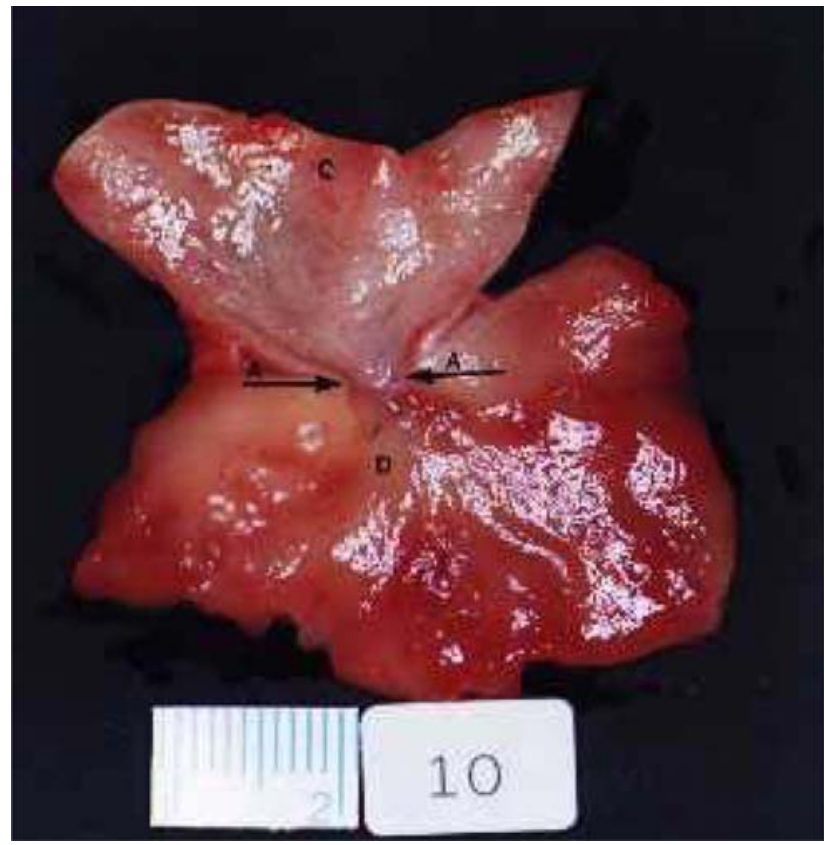

FIGURA 17 - Fotografia mostra peça operatória aberta longitudinalmente. Colédoco dilatado (C), anastomose diminuída (A) e duodeno (D). Suíno 10. Grupo I.

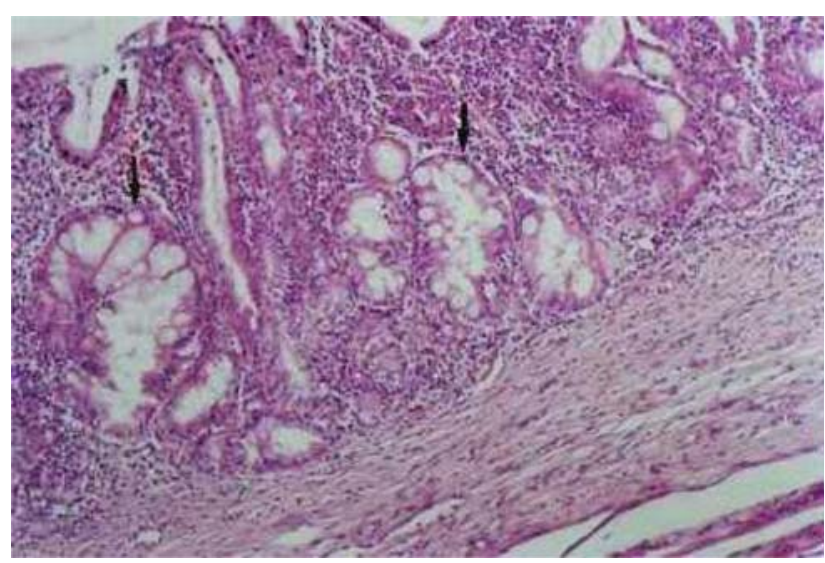

FIGURA 19 - Fotomicrografia mostra glândulas do tipo intestinal (metaplasia intetinal) no colédoco. (seta 1). Aumento 158x. Coloração pela hematoxilina-eosina. Suíno 16. Grupo II

Acta Cirúrgica Brasileira - Vol 20 (1) 2005 - 81 


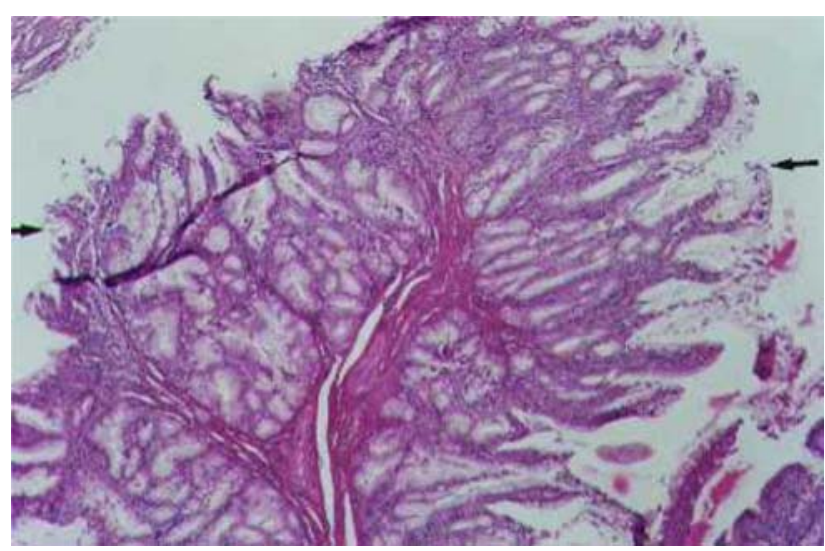

FIGURA 20 - Fotomicrografia mostra região da eversão com hiperplasia da mucosa. Suíno 16. Grupo II. Aumento 63x. Coloração pela hematoxilinaeosina.

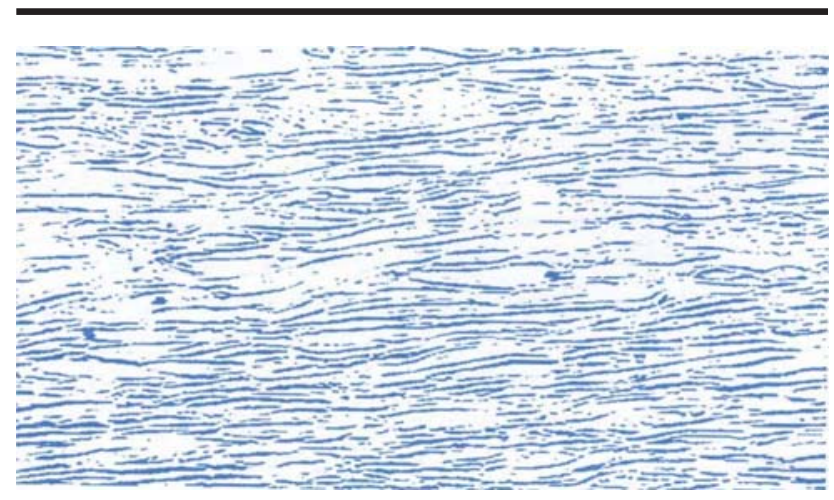

FIGURA 21 - Imagem digitalizada das fibras elásticas captadas da lâmina corada pelo método fúcsina-resorcina de Weigert

\section{Discussão}

Na realização da anastomose coledocoduodenal, a técnica original proposta por Mammana ${ }^{5,6,7}$, consiste em fixar a porção evertida do colédoco com três pontos. Após a fixação a parte evertida era suturada na mucosa duodenal. Um segundo plano era realizado entre a sero-muscular do duodeno e a fibromuscular do colédoco.

A técnica realizada no grupo experimento foi modificada da técnica original, porque se verificou no grupo piloto, que em alguns animais esta eversão se desfazia. Resolveu-se então além dos três pontos de fixação, ancorar a fibromuscular do colédoco ao duodeno em toda a circunferência da anastomose, afastando a possibilidade de se desfazer a eversão.

O duodeno foi escolhido para o local da anastomose por ser de fácil acesso a exame endoscópico e por submeter as anastomoses ao contato do conteúdo duodenal.

O exame endoscópico foi realizado com a finalidade de evitar a formação de mais um grupo de estudo, para examinar precocemente a segunda fase da cicatrização, já que não teríamos nenhum conhecimento da evolução cicatricial da anastomose do grupo II .

Escolheu-se o décimo - quinto dia para o exame endoscópico, por ser o início da fase de maturação do colágeno ${ }^{8,9,10}$. Neste período o tecido cicatricial tem a mesma força tensil do tecido normal ${ }^{11}$.

A reoperação foi programada para se estudar a cicatrização mais tardia da anastomose. Escolheu-se o trigésimo dia para a reoperação porque neste período a reparação plástica está completa ${ }^{9,12}$. Foi demonstrado em anastomoses término-terminais em colédocos de cães, que com 28 dias as estenoses ocorreram em alta porcentagem ${ }^{13}$. Estudos em anastomoses esofágicas e afirmaram ser possível detectar com segurança as complicações mais tardias como a estenose em período de 30 dias $^{14}$.

Quando se analizou o D\% dos pesos dos animais, observou-se que não houve significância estatística, mostrando que o tipo de operação realizada em cada grupo, não interferiu na evolução ponderal (Tabela 1).

Na análise da ferida operatória, observaram-se dois abscessos nos animais do grupo I, um abscesso nos animais do grupo II e um abscesso nos animais do grupo III , estes achados estão dentro do esperado.

Encontrou-se uma única hernia incisional em um animal do grupo II .

Analisando as complicações intraperitoneais, detectou-se um único abscesso intraperitoneal, abaixo do lobo hepático direito, no suíno pertencente ao grupo simulado.

Nos três grupos estudados as aderências intraoperatórias junto ao colédoco eram firmes.

$\mathrm{Na}$ análise endoscópica observou-se uma tendência à diminuição do calibre da anastomose em um animal do grupo I. Neste mesmo animal durante o ato endoscópico, havia resíduos aderidos ao orifício da anastomose , mas não havia saída de bile. Nos demais ítens estudados, não foram registradas anormalidades.

Não foram encontradas na literatura referências sobre a fluxometria e pressão residual em suínos, com mesma metotologia empregada neste estudo.

A análise da fluxometria mostra que houve um 
aumento estatísticamente significante do fluxo nos grupos I e II, quando se comparou o fluxo na operação (F1 ) e na reoperação (F2). No entanto esta diferença não se observou no grupo III . Quando a anastomose é de bom calibre é de se esperar que o fluxo seja maior, foi o que ocorreu nos grupos I e II. No grupo III, como não houve procedimento sobre a papila ou anastomose o resultado foi semelhante na operação e reoperação.

Verificou-se que a resistência do esfincter de Oddi, em gatos, é raramente vencida por uma pressão inferior a 600mm de água ${ }^{15}$.

Em cães, comprovou-se que a pressão de secreção biliar do figado é aproximadamente de 30 cm de bile e foi estabelecido que a resistência oferecida pelo esfincter de Oddi é de 12 a $13 \mathrm{~cm}$ de solução salina isotônica ${ }^{16}$.

Outros estudos em cães mostraram que a pressão varia de 9 a 25 cm de soro fisilógico ${ }^{9,10,17}$.

A pressão nas vias biliares é regulada pelos seguintes fatores: Pressão secretora do fígado; volume da bile secretada no fígado; resistência do esfincter de Oddi e permeabilidade dos canais biliares ${ }^{18,19}$.

Horta e col. ${ }^{20}$, referiram que a medida da pressão existente em determinado setor das vias biliares extrahepáticas, aliada ao débito ou à quantidade de líquido que franqueia determinado segmento em um tempo dado, constitui o meio mais exato para ajuizar o estado funcional.

Estudos através de polígrafos via endoscópica, mostraram que a pressão do esfincter de Oddi em suínos é similar a dos seres humanos. No entanto a canulação do esfinter de Oddi para se fazer a manometria é muito difícil. É necessário um treinamento em colangiopancreatografia retrógrada para se realizar tal procedimento, o que limita sua aplicação ${ }^{21}$. O método também pode acarretar pancreatite em podendo chegar a $17 \%$ dos $\operatorname{casos}^{22}$.

Há ainda o incoveniente de necessitar um conjunto de equipamentos muito caros que inviabiliza o seu uso em nosso meio ${ }^{23}$.

Encontrou-se no grupo grupo III a média de

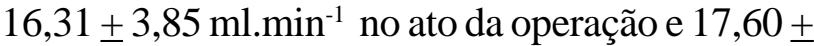
3,83 ml.min ${ }^{-1}$ na reoperação.

Neste estudo encontrou-se com a metodologia utilizada no grupo simulado, pressão média de 6,30 $\pm 2,23 \mathrm{~cm}$ de água na operação e 6,10 $\pm 1,76 \mathrm{~cm}$ de água na reoperação.

Quando se analisou a pressão residual na operação (PRF1) e na reoperação (PRF2), notouse que o resultado foi o inverso da fluxometria, isto é, estatísticamente a PRF2 foi menor do que a PRF1 no grupo I e II. As considerações são as mesmas da fluxometria.

A dilatação do colédoco após a colecistectomia no cão foi constatada experimentalmente por Judd e Mann ${ }^{24}$, os quais concluíram que a dilatação pode ser entre duas a três vezes o calibre inicial do colédoco. No entanto não observaram dilatação intra-hepática ${ }^{18}$. O tempo para ocorrer esta dilatação é variável, podendo chegar até 60 dias $^{18}$.

Outros autores não encontraram dilatação do colédoco em cães após colecistectomia. Utilizaram ultra-som e tomografia computadorizada no pósoperatório de colecistectomia em cães, verificaram que a dilatação do colédoco é mínima ${ }^{(25,26)}$.

Neste estudo quando se comparou o diâmetro do colédoco na operação e reoperação, verificou-se que houve um aumento estatisticamente significante do calibre do colédoco, nos grupos I, II e III. Quando foram comparadas dilatações entre os três grupos, notou-se que não houve diferença estatisticamente significante. O aumento do calibre do colédoco no grupo III, mostra que a colecistectomia influenciou no aumento do diâmetro do colédoco nesse grupo.

Quando se retirou a vesícula biliar, houve um fluxo contínuo de bile em direção ao duodeno. Como o esfincter de Oddi encontra-se íntegro, este apresenta resistência a esse fluxo biliar, dilatando a via biliar ${ }^{18}$. Este fato explica a dilatação dos colédocos no Grupo III.

Ao se estudar o calibre das anastomoses observou-se que no grupo I a media do calibre da anastomose foi $4,52 \pm 2,62$ e grupo II 4,58 $\pm 1,25$, portanto este não foi o fator que deteminou as dilatações em quase todos os colédocos dos grupos I e II. Quando se compara o diâmetro das anastomoses entre os grupos I e II verifica-se que não há diferença estatisticamente significante entre os grupos.

O único fator presente nos grupos I e II e não no grupo III é o refluxo duodenal.

Após a coledocoduodenostomia a mucosa do colédoco é exposta a uma nova situação isto é ao refluxo de secreção duodenal, que anteriormente era protegida pelo esfincter de Oddi ${ }^{27}$.

A integridade do esfincter de Oddi, permite regular o fluxo biliar para o duodeno e a realizações de derivações bilioentéricas a fim de restaurar o fluxo 
biliar para o aparelho digestivo, não consegue restabelecer a efetividade dos mecanismos antirefluxo, e invariavelmente este ocorre ${ }^{28,29}$.

Na revisão da literatura não foram encontrados estudos em suínos com a metodologia utilizada, para se poder cotejar estes resultados; no entanto, estudos em ratos, observou-se que em colédoco-coloanastomose e colédoco-duodeno-jejunoanastomose, foram encontrados um aumento estatísticamente significante do diâmetro dos colédocos. Os autores sugeriram que o refluxo pancreático e do conteúdo intestinal, causando um processo inflamatório nesses colédocos, seja um fator que contribuiu para a referida dilatação ${ }^{30}$.

Kato e col. ${ }^{31}$, foram os primeiros a produzirem dilatação cística do colédoco fazendo a pancreaticocolecistostomia. Miyano e col..$^{32}$ usaram a coledocopancreaticostomia para produzir os mesmos efeitos e Ohkawa e col. ${ }^{33}$ realisaram estudos experimentais em cães anastomosando o ducto pancreático ao colédoco e concluiram que o refluxo pancreaticobiliar causa danos na árvore biliar.

Benhidjeb e col. ${ }^{36,}$ reproduziram refluxo duodenal para o colédoco em mini porcos. Observaram dilatação cística em todos os animais e diminuição das fibras elásticas após duas semanas de pós operatório.

Kurumado e col. ${ }^{34}$, estudando coledocoenterostomia em ratos observaram uma importante dilatação do colédoco mimetizando a doença em humanos chamada dilatação cística congênita do colédoco e chamou a atenção para o intenso refluxo pancreatico e intestinal para o interior do colédoco. Neste artigo faz uma correlação de que os pacientes com dilatação cística congênita do colédoco têm uma alta incidência de confluencia anormal do ducto pancreatico e o colédoco ${ }^{30}$.

Babitt e col. ${ }^{35}$ postularam uma teoria de que uma anomalia da junção biliopancreática (congênita) impede o desenvolvimento do esfincter na junção do colédoco e ducto pancreático, permitindo o refluxo do suco pancreático para o colédoco por um gradiente de pressão do ducto pancreático (de $50 \mathrm{~cm}$ de água) para o colédoco ( $30 \mathrm{~cm}$ de água), produzindo surtos de colangite. Postularam que como conseqüência do refluxo da secreção pancreática para o colédoco ocorre inflamação, fibrose, e finalmente a dilatação cística ${ }^{35,36}$.

Ohkawa e col. ${ }^{33}$ em estudos experimentais em cães e Benhidjeb e col. ${ }^{36}$ em porcos concluíram, que o refluxo pancreaticobiliar causa danos na árvore biliar e notaram diminuição das fibras elásticas na parede do colédoco.

Por este motivo resolveu-se estudar o conteúdo de fibras elásticas no colédoco.

A análise estatística destes valores mostrou que a percentagem de fibras elásticas é menor nos grupos I e II.

De acordo com a literatura citada, esta diminuição das fibras elásticas nos grupos I e II faz-nos supor que o refluxo do conteúdo duodenal tenha sido o responsável por este dano ${ }^{30,31,33,34,35,36}$.

O exame macroscópico na zona da anastomose quanto aos aspectos de coaptação da mucosa e da fibromuscular foram bons nos grupos I e II.

Como no grupo piloto tivemos alguns animais em que a eversão se desfez, o estudo histológico comprovou que a eversão da parede do colédoco esteve presente até a reoperação em todos os animais do grupo II.

Quanto às coaptações da mucosa e da fibromuscular, histológicamente foram boas em todos os animais do grupo I e do grupo II .

A presença de tecido cicatricial esteve presente na linha de sutura em todos os animais do grupo I e II.

Houve erosão na linha de sutura, encontrada em um animal do grupo I e em dois animais do grupo II, não interferindo no resultado final da cicatrização.

Sob o ponto de vista histológico, nos grupos I e II, não foram detectadas na linha de sutura necrose ou úlcera.

Quanto à reação inflamatória caracterizada por infiltrado linfo-monocitário, infiltrado de neutrófilos, foi semelhante nos grupos I, II e III. A reação de corpo estranho também foi semelhante entre os grupos. Nos grupos I e II como houve sutura, este tipo de reação era esperado. No grupo III , como não houve sutura esta reação provavelmente se deveu a ligaduras com fios de vasos, realizadas no tecido pericoledociano.

Estudos das alterações histológicas após anastomoses colédoco-duodenal no ser humano entre 1 a 12 anos de pós - operatório, realizou biópsias endoscópicas na parede posterior do colédoco, encontrando em todos os pacientes hiperplasia superficial das celulas epiteliais e ocasionalmente metaplasia, que normalmente não é encontrada neste epitélio. Também, encontrou-se um 
intenso infiltrado inflamatório com linfócitos polimorfonucleares e fibrose. Estes autores afirmam que o grau de adaptação depende de três fatores: quantidade de tecido retirado, segmento envolvido na reconstrução e a presença ou ausência de refluxo intestinal, concluindo que a mais significante adaptação do tecido coledociano é a metaplasia.

Estas alterações também foram encontradas após papilotomia em cães.

A metaplasia é uma alteração reversível no qual uma célula adulta (epitelial ou mesenquimal), é substituída por outra célula adulta. A metaplasia também representa uma substituição adaptativa de células mais sensíveis ao estresse, por células mais capazes de suportar o ambiente adverso. No entanto, se as influências que predispuseram a metaplasia continuarem a persistir, podem induzir a transformação maligna no epitélio metaplásico ${ }^{32}$.

Metaplasia pseudopilórica e metaplasia intestinal são encontradas freqüentemente no epitélio adjacente aos cânceres de vesícula biliar e são consideradas as bases da carcinogênese ${ }^{30}$.

Neste experimento chamou a atenção a presença de metaplasia intestinal nos colédocos dos grupos I e II, sendo estatisticamente significativamente maior do que no grupo III. Neste último grupo a alteração histológica não ocorreu.

A hiperplasia é uma importante resposta das células do tecido conectivo na cicatrização de feridas, nos quais a proliferação de fibroblastos e vasos sangüíneos ajudou no reparo ${ }^{32}$.

A hiperplasia epitelial foi encontrada em 3 animais do grupo II, e não encontrada nos animais do Grupo I e III, este achado não teve significância estatística e faz parte do processo de reparação tecidual.

As demais alterações epiteliais como atipia e atrofia, não foram encontradas em nenhum animal dos três grupos de estudo.

\section{Considerações Finais}

O escopo deste experimento não foi demonstrar o refluxo duodeno-biliar, mas é evidente que isto ocorreu, pois na técnica estudada, não há reconstrução do mecanismo anti-refluxo.

No campo experimental há diversos trabalhos mostrando os efeitos nocivos do refluxo do conteúdo intestinal e principalmente pancreático para o colédoco ${ }^{30,31,33,36}$.
Nagata e col. ${ }^{18}$ associaram o refluxo pancreatico biliar como causa de carcinoma na via biliar.

Miyano e col..$^{32}$ reproduziram em estudo experimental em cães o refluxo coledocopancreático observando a formação de adenomas em $44 \%$ dos animais.

No presente estudo demonstrou-se que nos colédocos das anastomoses colédoco-duodenais em porcos há metaplasia intestinal, diminuição das fibras elásticas e dilatação.

Estudos destas alterações epiteliais em diversos tempos pós-operatórios podem vir a contribuir para o esclarecimento e a seqüência progressiva da modificação do epitélio biliar.

Oproblema do refluxo do conteúdo intestinal para o colédoco é um ponto decisivo na agressão do epitélio biliar e deve-se empregar técnicas no qual este refluxo possa ser evitado.

No grupo experimento não houve diminuição do diâmetro da anastomose em nenhum animal. Não se pode chegar a conclusão categórica que neste tipo de procedimento a estenose não ocorra. Novos estudos deverão ser feitos em outros tipos de animais e com períodos de tempo maiores para chegar a conclusões mais confiáveis.

\section{Conclusões}

1 - A anastomose colédoco duodenal términolateral provoca aumento do calibre coledociano, com ocorrência de metaplasia intestinal ou diminuição de fibras elásticas no colédoco de suínos.

2 - Não há diferença nos resultados entre as técnicas com e sem eversão da mucosa do colédoco e sua implantação no intestino.

\section{Referências}

1. Moseley RH, Boyer JL. Mecanisms of eletrolite transport in the liver and their functional significance. Semin Liver Dis. 1985;5:137-47.

2. Goffi FS, Goffi Jr PS. Cirurgia das vias biliares: restauração do trânsito biliar. In: Goffi FS. Técnica cirúrgica: bases anatômicas, fisiopatológicas e técnicas da cirurgia. 4 ed. São Paulo: Atheneu; 1996. p.711-5.

3. Lillemoe KD, Melton GB, Cameron JL, Pitt HA, Campbell KA, Talamini MA, Sauter PA, Coleman J, Yeo CJ. Postoperative bile duct strictures : management and outcome in the 1990s. Ann Surg. 2000;232(3):430-41.

4. Rasslan S; Pacheco Jr AM, Silva RA, Soldá SC, Casaroli AA, Fava J . Reoperações sobre as vias biliares. GED. 
1993; 12: 88-92.

5. Mammana CZ. Anastomoses das vias biliares. In Cirurgia das vias biliares: técnica e tática cirúrgicas. São Paulo: Editora Policor; 1981.

6. Parrilla P, Ramirez P, Sanchez Bueno Fperez JM, Candel MF, Muelas MS, Robles R. Long term results of choledochoduodenostomy in the treatment of choledocholithiasis: assesment of 225 cases. Br J Surg. 1991;78(4):470-2.

7. Mammana CZ. Coledocoduodenostomia e hepáticogastrostomia papilar. Folha Médica. 1968; 57:39-49.

8. Fellows NM, Burge J, Hatch CS, Price PB. Suture strenght and healing strenght of end-to- end intestinal anastomoses. Surg Forum. 1951;2:111-7.

9. Van Winkle W, Hastings C. Considerations in the choice of suture material for various tissues. Surg Gynecol Obstet., 135:113-26, 1972.

10. Jiborn H, Ahonen J, Zederfeldt B. Healing of experimental colonic anastomoses: bursting strenght of the colon after left colon resection and anastomosis. Am J Surg. 1980;136:587-94.

11. Hobsley M. Wound healing. J R Soc Med. 1982;75:820-3.

12. Howes EL, Sooy JW, Harvey SC. The healing of wounds as determined by their tensile strenght. J Am Med Assoc. 1929;92:42-5.

13. Douglass TC, Lounsbury BF, Cutter WW, Wetzel N. An experimetal study of healing in the common bile duct. Surg Gynecol Obstet. 1958;91:301-05.

14. Nigro AJT. Anastomose esôfago-esofágicas cervicais término-terminais em dois planos de sutura, em plano único extramucoso e por invaginação: estudo comparativo experimental em cães [Tese - Livre Docência]. Universidade Federal de São Paulo, Escola Paulista de Medicina; 1990.

15. Sokal RR, Rolhf FJ. Biometry. San Francisco: W. H. Freeman; 1969.

16. Achibald B. The experimental production of pancreatites in animal as the result of persistence of the common duct sphincter. Surg Gynecol Obstet. 1919;28:529-45.

17. Miranda M, Espinoza M, Csendes A. Manometric characteristics of the extrahepatic biliary tract in dogs. Dig Dis Sci. 1981;26: 417-22.

18. Nagata E, Sakai K, Kinishita H, Kobayashi Y. The relation between carcinoma of the gallbladder and an anomalous connection between the choledochus and the pancreatic duct. Ann Surg. 1985;202:182-90.

19. Bevilaqua RG, Margarido NF, Soares LA, Mansur Koch V, Gonçalves EL. Efeitos da perfusão no colédoco com soluções de ácidos biliares sobre a atividade do esfincter de Oddi. Rev Bras Pesq Med Biol. 1979;12:177-83.

20. Horta ACL. Avaliação da permeabilidade, da porção terminal do ducto colédoco pela medida do débito (com referência a manometria biliar) [Tese Doutorado].Faculdade de Medicina da Universidade de São Paulo; 1954.
21. Freys SM, Heimbucher J, Fuchs KH. Teaching upper gastrointestinal endoscopy: the pig stomach. Endoscopy. 1995;27:73-6.

22. Silva GSP.Dinâmica do sistema biliar. Rev Bras Med. 1951;8(12):847-9.

23. Soares LA, Bevilacqua RG, Koch V, Margarido NF, Osaka JT, Gonçalves EL. Ação de contraste iodado na atividade motora da junção colédoco-terminal.Estudo experimental. Rev. Hosp Clin Fac Med São Paulo. 1982;37:167-70.

24. Judd E, Mann FC. The effect of removal of the gallbladder. An experimental study. Surg Gynecol Obstet. 1917;24: 437-42.

25. Mahour GH, Wakim KG, Soule EH, Ferris DO. Effect of cholecystectomy on the biliary ducts in the dog. Arch Surg 1968;97:570-4.

26. Mahour GH, Wakim KG, Ferris DO, Soule EH. Canine common bile duct. Arch Surg. 1969;98:239-40.

27. Bhatngar KK, Samuel KC, Goyal RA. An experiental study of biliary ducts in dogs after cholecystectomy. Indian J Med Res. 1972;60:1498-502.

28. Raptoulos V, Fabian TM, Silva W, D’orsi CJ, Karellas A, Comptom CC, Krolikowsski FJ, Doherty P, Smith EH. The effect of time and cholecystectomy on experimental biliary tree dilation: a multiimaging evaluation. Invest Radiol. 1985;20:276-86.

29. Eleftheriadis E, Tzioufa V, Kotzampassi K, Aletras H. Common bile duct mucosa in choledochoduodenostomy patients: histological and histochemical study. HPB Surg. 1988;1:15-20.

30. Villegas-Alvares F, Hernández-Gonzáles R, CandonosaAranda E, Avila-Ramirez E, Cravioto-Munoz J. Derivación bilioentérica convergente con mecanismo antirreflujo: estudio experimental. Bol Med Hosp Infant Mex. 1990;47:342-8.

31. Kato T, Asakura Y, Kasai M. An atttempt to produce choledochal cyst in puppies. J Pediatr Surg. 1974;12:509-13.

32. Miyano T, Suruga K, Suda K. Adenoma and stone formation of biliary tract in puppies that had choledochopancreatic anastomosis. J Pediatr Surg. 1989;24:539-42.

33. Ohkawa H, Sawaguchi S, Yamazki Y, Ishikawa A, IbarakiKen MK. Experimental analysis of the ill effect of anomalous pancreaticobiliary ductual union. J Pediatr Surg. 1982;17(1):7-13.

34. Kumurado K, Nagai T, Kondo Y, Abe H. Long term observations on morphological changes of choledochoenterostomy in rats. Dig Dis Sci. 1994;39(4):809-20.

35. Babbitt D, Starshak J, Clemett AR. Choledochal cyst: a concept of etiology. Am J Roentgenol. 1973;119(1):57-62.

36. Benhidjeb T, Said S, Rudolph B, Siegmund E. Anomalous pancreatico-biliary junction: report of new experimental model and review of the literature. J Pediatr Surg. 1996;31(12):1670-4. 
Correspondência:

Murched Omar Taha

Rua Botucatu, 740

04023-900 São Paulo - SP
Conflito de interesse: nenhum Fonte de financiamento: nenhuma

Recebimento: 15/09/2004

Revisão: 22/10/2004

Aprovação: 30/11/2004

\section{Como citar este artigo:}

Nascimento LR, Taha MO, Fagundes DJ, Gomes PO, Novo NF. Anastomose coledocoduodenal término-lateral em plano único com eversão da parede do colédoco em suínos. Acta Cir Bras. [serial online] 2005 Jan-Fev;20(1). Disponível em URL: http://www.scielo.br/acb

*Figuras coloridas disponíveis em www.scielo.br/acb 